\section{CHINATOWN IN BANGKOK: THE MULTILINGUAL LANDSCAPE}

\author{
Hongmei $W u^{1}$ \\ Sethawut Techasan ${ }^{2}$
}

\begin{abstract}
This paper examines the linguistic landscape (shop names) of Chinatown in Bangkok, a prosperous minority language (Chinese) community of diverse commercial establishments. Informed by an ethnographic framework, it explores the preservation of Chinese language and culture under the circumstance of language contact with Thai, the majority language, and globalization influence of English. Unsurprisingly, the inherited Chinese language (dialects as Teochew or Cantonese) was lost in the $2^{\text {nd }}$ or $3^{\text {rd }}$ generation of the Chinese descendants in Chinatown. However, the shop names suggest that in part because of its commodifying value and cultural awareness of the current proprietors, the Chinese shop owners are inclined to preserve the Chinese language and culture of the shops through the use of traditional Chinese characters, colors, layout and other marks of the shops. On the other hand, an analysis of the mutual translations of Chinese and Thai indicates that Chinese has more of a symbolic rather than informative function for Thai monolingual customers. Moreover, the
\end{abstract}

\footnotetext{
${ }^{1} \mathrm{Ph}$. D. Student, English as an International Language Program, Chulalongkorn University, Bangkok.

2 MA. Student, English as an International Language Program, Chulalongkorn University, Bangkok.
}

ascendancy of English has contributed to the complexity of the multilingual landscape in Bangkok's Chinatown.

\section{Introduction}

Chinatown in Bangkok is one of the most famous tourist destinations in Thailand. It refers to the area in Samphanthawong district which includes many roads, such as Yaowarat Road, Charoen Krung Road, Mangkon Road, Song Wat Road, Song Sawat Road, and Chakkrawat Road, etc. Chinatown is also known by Thai people as 'Yaowarat', which derives from the name of one of the roads in Chinatown area. The path of the road is said to resemble a dragon's body, making it an auspicious location for business. There are many small alleys lined with shops and vendors selling various types of goods. When local people or tourists talk about Chinatown in Bangkok or Yaowarat, they tend to mean the area along Yaowarat road which is the main center for trading by Chinese community.

Bangkok's Chinatown has a very long history, predating the name itself. Chinese traders and craftsmen settled in Thailand in the $16^{\text {th }}$ century during the Ayutthaya period. By 1700, about 3000 Chinese had settled there. When King Rama I ascended the throne in 1782, he moved the capital of Siam from the west bank to the east bank of the Chao Phraya river, an area already occupied by a large community of Chinese immigrants, who settled there during the reign of the previous monarch, King Tak Sin. With the shift of the capital, members of this community who were forced to abandon their businesses moved southward and settled along the eastern bank of the river. From there, the new Chinatown rapidly expanded to the east and south. In the $1820 \mathrm{~s}$ and $1830 \mathrm{~s}$, thousands of Chinese, mostly from 
southern China, immigrated to Siam and many of them settled in and around the capital. During the latter half of the Nineteenth and first half of the Twentieth Centuries, immigration from China continued, in part due to floods, draughts and domestic conflicts in that country.

Now along Yaowarat Road, most if not all shopkeepers are descendants of these and subsequent immigrants. Born, raised and educated in Thailand, they identify as both Thai and Chinese-Thai. Many have adopted Thai family names, but many also retain a Chinese name as well. They speak Thai, and even though most claim Teochew as their heritage language, some are not able to speak it. At the same time, most speak at least a minimal level of the international language of English and are also clearly aware of the rising influence of China and Mandarin in Thailand, the region, and the world. In this complex language contact situation, players negotiate multiple identities played out in, among other venues, the linguistic landscape along Yaowarat Road.

\section{Literature Review}

In recent years, a large number of academic papers and theses or dissertations have explored the linguistic landscapes (LLs) from different perspectives following the definition in Landry and Bourhis (1997:23-49): "The language of public road signs, advertising billboards, street names, place names, commercial shop signs, and public signs on government building combines to form the linguistic landscape of a given territory, region, or urban agglomeration" (from Huebner, 2009:70). Starting from this definition, research on linguistic landscape has ranged from cityscapes (urban LL studies) to virtual space (web
1.0, web 2.0\& web 3.0). Scholars have explored linguistic landscape from a variety of angles, such as the promotion of multilingualism, the implementation of language policy, the preservation of minority languages, the effects of English globalization, and the application of linguistic landscape analysis as a pedagogical tool. Huebner (2006) investigated the linguistic landscapes of fifteen Bangkok neighborhoods to explore questions of language contact, language mixing and language dominance. Backhaus (2006) conducted an empirical study of multilingual signs in Tokyo. BruyèlOlmedo (2015) studied the relationship between languages (Catalan \& Spanish) and tourism in Mallorca, Spain. Moriarity (2015) examined the linguistic landscape (LL) of Dingle in Ireland and plotted the trajectory of the Irish language as a resource for indexing Dingle as an authentic tourist space. Cenoz \& Gorter (2006) compared the linguistic landscapes of two distinct European settings, Basque Spain and Frieseland Netherlands, with respect to the use of the minority language (Basque or Frisian), the state language (Spanish or Dutch) and English as an international language. Their findings reflect differences in status and in language policy regarding the minority languages and to the spread of English in Europe. Lawrence (2012) utilized sociolinguistic theories of social stratification, gravity and cascade models to analyze the usage of English in the linguistic landscape of Korea. Ivkovic \& Lotherington (2009) argued that the LL of virtual space, though grounded in the concept of multilingual interactions within a physically defined world, has characteristics unique to the digital world that continue to evolve conterminous with the complex relationship of the real to the digital. Lou (2010) investigated the 
commodification and marginalization of Chinatown in Washington DC through a study of its linguistic landscape. This paper aims to examine the linguistic landscape (shop names) of the Chinatown area of Bangkok, a prosperous minority language community with a diverse and vibrant commercial life. It attempts to address the question 'How does the linguistic landscape Chinatown reflect its residents' negotiations of multiple identities and attempt to preserve Chinese language \& culture under the circumstance of language contact with the majority language Thai and English globalization?'

\section{Methodology}

Our research focuses on the Linguistic Landscape of Yaowarat Road, a main road in Chinatown, Bangkok. Two sides of the road are lined with stores selling gold, garments, souvenirs, second-hand goods, electric goods, antiques, imported musical instruments, furniture, and local delicacies. There are various multilingual signs along the road, ranging from small shop names on the store front to the giant signs hanging perpendicular to the building on the second and third floors. Many different languages, such as Thai, Chinese, English, Japanese, and Arabic, can be found in the signs along Yaowarat Road. The road is 1,410 meters long starting from the Odean Circle to the Peerapong Intersection.

We limited the area of our research to only 900 meters from the Odean circle to the intersection with Ratchawong Road because the selected areas are the areas where the most active trading takes place. The excluded areas are generally the residential areas with few shops. We collected the data from 140 shops along both sides of the road. The unit of analysis was restricted to the permanent shop signs containing shop name. Three types of shop signs were analyzed. The first type is the signs above the door and window on the store front which indicate the name of the shop. The second type is the extended signs that emerge overhead and perpendicular to the front of the shop, so that people walking along the pavement can clearly see them. The last type is the shop name appearing on the shop doors and windows. All of the signs used for data analysis were limited to only the first floor of the shops, excluding the huge shop signs in the upper floors and other signs that do not indicate the shop's name, such as 'push', 'pull', or 'welcome' sign. A total 274 pictures of shop signs were taken by IPhone 4S.

Moreover, interviews were conducted with thirty-six interviewees to seek their background information, the owners' intentions conveyed in the shop name and attitude towards the Chinese language and culture. Twenty-six interviews were with Chinese-Thai shop owners from three generations. Three were first generation immigrants. Eighteen were second and five were third generation Chinese-Thais. One of the interviewees is a Muslim shop owner and another is of unknown ethnicity. We also interviewed eight other people who are not shop owners. Seven of them are shop employees and another one is a customer. The questions were about the reason for choosing this name as a shop name, the target audiences of the shop name, the owners' background, language literacy, and attitude toward Chinese language and culture, as well as government policy on shop signs. 


\begin{tabular}{|l|c|c|c|}
\hline \multicolumn{1}{|c|}{ Language } & Major Sign & Extended Sign & Doors \& Windows \\
\hline Thai & 128 & 44 & 13 \\
\hline Chinese & 104 & 36 & 9 \\
\hline English & 73 & 18 & 3 \\
\hline Arabic & 1 & 0 & 0 \\
\hline Japanese & 0 & 1 & 1 \\
\hline
\end{tabular}

Table 1: Language appearing on different types of shop sign

\section{Results}

\section{Quantitative Results}

One indication of the multiple identities being negotiated in Chinatown is manifested in the languages appearing in the linguistic landscape. Table 1 illustrates the languages appearing on the shop signs in Chinatown, Bangkok. Almost all of the shops have a major sign, which is the sign on the store front above the door and window indicating the name of the shop. Some shops also have extended signs, accompanying the major signs, so that customers on foot can see them easily. A few shops also have their names on the doors or windows themselves. It can be seen that the language which appears most frequently in all three types of shop signs is Thai, even though Chinatown is considered a Chinese community. One reason for this is that the majority of customers and shop owners can read Thai but not Chinese. Another factor concerns the law. A government policy states that shop signs must contain Thai script or be taxed at a higher rate.

The Chinese language appears second most frequently on the signs. The presence of Chinese reflects the unique identity of Chinatown. Some shop names are originally in Chinese, with Thai transliteration from the pronunciation of Teochew dialect, because the shop owners of the first generation are immigrants from the southern region of China. These transliterations into Thai allow Thai speakers to identify, pronounce and perhaps understand the name of the shop. The Chinese orthography, on the other hand, allows non-Teochew-speaking Chinese-Thai and Chinese-speaking customers from Singapore, China, Malaysia, Taiwan and Hong Kong to understand the meaning of the name, despite dialect differences.

Due to globalization, English also has an influence on the shop signs. English reflects the internationalization of both proprietors and customers. Signs with English names serve the symbolic function of lending more prestige to the shop. The use of English also has an informative function in that they communicate with foreign customers and tourists from nonChinese-speaking countries. 


\begin{tabular}{|l|c|c|c|}
\hline \multicolumn{1}{|c|}{ Languages } & $\begin{array}{c}\text { Major } \\
\text { Sign }\end{array}$ & $\begin{array}{c}\text { Extended } \\
\text { Sign }\end{array}$ & $\begin{array}{c}\text { Doors \& } \\
\text { Windows }\end{array}$ \\
\hline Monolingual English & 6 & 3 & 1 \\
\hline Monolingual Thai & 14 & 10 & 3 \\
\hline Monolingual Chinese & 1 & 4 & 1 \\
\hline Bilingual English-Thai & 11 & 4 & 1 \\
\hline Bilingual English-Chinese & 1 & 2 & 0 \\
\hline Bilingual Thai-Chinese & 47 & 21 & 7 \\
\hline Bilingual Thai-Arabic & 1 & 0 & 1 \\
\hline Multilingual English-Thai-Chinese & 55 & 8 & 1 \\
\hline $\begin{array}{l}\text { Multilingual English-Thai-Chinese- } \\
\text { Japanese }\end{array}$ & 0 & 1 & $\mathbf{1 5}$ \\
\hline TOTAL & $\mathbf{1 3 6}$ & $\mathbf{5 3}$ & \\
\hline
\end{tabular}

Table 2: The monolingual, bilingual and multilingual shop's signs

Table 2 presents the classification of three types of signs into monolingual, bilingual and multilingual signs. Out of 140 shops, 136 have a major sign on the store front. The majority of the major signs contain more than one language. Approximately $40 \%$ of the major signs are multilingual English-Thai-Chinese. Almost 35\% of the major signs are bilingual Thai-Chinese. In contrast, the majority of the extended signs are bilingual, mostly Thai-Chinese. These extended signs seem to be intended for the primary customers in Chinatown, namely Thai and Chinese. Like the extended signs, signs on doors and windows are mostly bilingual.

Thai is the most commonly found language in the shop names, followed by Chinese and English respectively. However, on monolingual major signs, English appears more often than Chinese. There are six monolingual English signs whereas there is only one monolingual Chinese sign. Most monolingual English major signs are of multinational franchises or hotels that cater to customers who can read English. All three types of signs display multiple languages in order to communicate with wider target audiences, but also to express the shop owners' own multiple identities.

\section{Qualitative Results}

From the interviews, we found that the Chinese immigrants who originally settled in Chinatown and built their businesses initially could not speak Thai, but because of language contact with Thai, they eventually were able to speak and understand the national language. As businesses were passed down to subsequent generations, the second generation could communicate in both languages, Thai and Chinese, because they were taught in Thai at school and used Chinese at home. However, the second generation might not be literate in Chinese since the government restricted Chinese teaching in school during Thailand's Nationalism period between 1930s and 1950s under the government of Prime Minister Plaek Pibunsongkram. As reported in 'การศึกษาภาษาจีนในประเทศไทย ตอนที่ ๓ http://www.oknation.net/blog/sirinui/2012/ 06/03/entry-1' retrieved from www.oknation.net (19 December 2015) and 'Thai Chinese' retrieved from Wikipedia (20 December 2015), the 
primary Education Act 1932 allowed the students to study Mandarin for two hours per week. Chinese schools were under control of the Thai government and some that violated the rules were forced to shut down. Later in the 1970s, Chinese was allowed to be taught in primary school, and since 1990s it has been allowed to be taught as a second language.

In addition to Chinese courses taught in school, another institution central to the language shift situation in Chinatown is the clan-based associations whose aims are to support their members in business or to communicate with each other to enhance intra-clan relationships. Interestingly interviewees reported that the language used in the associations is mostly Thai, though some elders still speak Chinese (Teochew) among themselves and pass on stories of the community's ancestral roots to younger generations.

While parents have always until this day been supportive of their children learning Chinese, what has been taught is Mandarin, not the language of their ancestors and the language still spoken by the older members of the Chinatown community (Teochew, Hakka, or Cantonese). Ninety percent of Chinese descendants come from Chaozhou China, speaking Teochew; others speak Cantonese and a few speak Mandarin Chinese. Today, some one-third of present generation shop owners are still able to speak Chinese (Teochew) if their parents speak it, but they may also be illiterate in Chinese, since Thai and English are the only mandatory languages taught in school. Among younger residents, Mandarin Chinese is a symbol of the dynamism of an increasingly assertive mainland China, the emerging economic powerhouse in the region (Kasanga,
2012:561), though it is not the language of their ancestors.

In the midst of this on-going language shift, attempts at preservation of the heritage language and culture are manifested not only in institutions like schools and cultural associations but also in the symbolic functions of Chinese in the linguistic landscape of Yaowarat Road, for example, in the choice of shop names, in the bilingual arrangement of information and in the spatial organization of the languages in those signs. Teochew dialect is widely used in transliteration of the shop names from Chinese script to either English, Thai or both. While the generational shift from Chinese to Thai is reflected in the predominance and prominence of Thai in the linguistic landscape of Chinatown, members of the Chinatown community that we spoke with are aware of the increasingly important role of Chinese in today's global society and they encourage their children to learn both English and Chinese, though the Chinese studied is not the dialect of their parents and grandparents.

\section{Discussion}

\section{Categorization of Shop Names}

One obvious manifestation of the heritage language and culture of Chinatown can be found in the selection of shop names. We have sorted the shop names into six categories based on the content. First of all, most of the shop names with Thai and Chinese characters derive from the first name or last name of the shop owners. As shown in Picture 1, the shop selling imported fruits was named after two cofounders with their first name 'Chang' (長 ) and ' $F u$ ' (富). But the Thai transliteration of the Chinese name is based on the 
Teochew dialect of Chinese, 'Chiang-Pu', the most widely spoken Chinese dialect spoken by the Chinese-Thai in Chinatown and their ancestors.

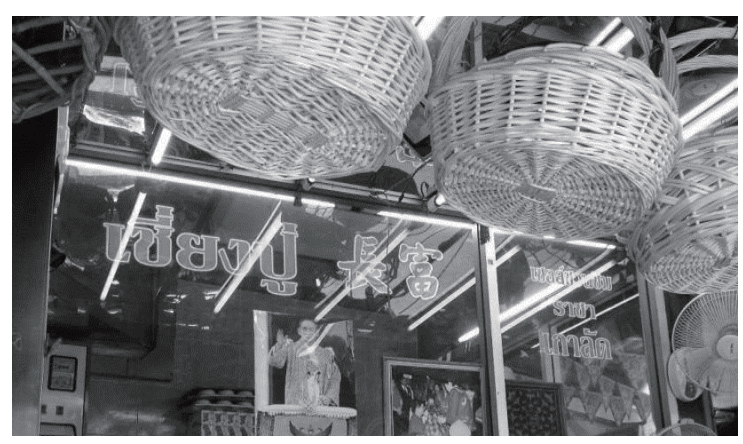

Picture 1: A shop selling imported fruit

The second category of shop names includes those that indicate the product it is selling. Picture 2 shows the shop name on the sign above the glass door. The Thai and English scripts both contain the family name of the shop owner (Lao Li) and its specialty (shark's fin). The Chinese script, on the other hand, provides additional information, stating that the shark fin is imported. The main purpose of the name is to communicate to customers that shark's fin, a uniquely typical Chinese fare, is available here.

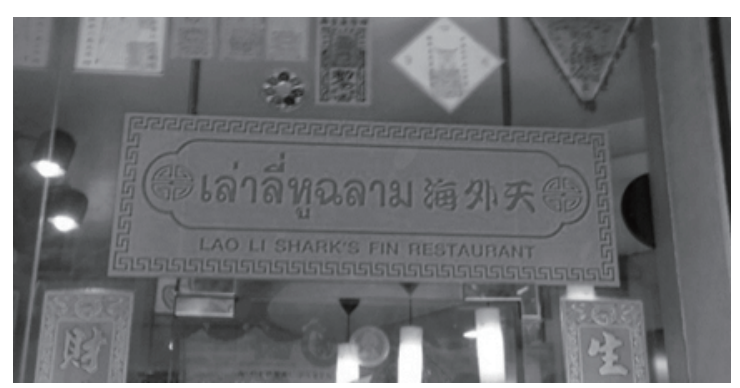

Picture 2: A shark fin restaurant in Chinatown
Some shop names present information about the origin of the shop. Picture 3 is a picture of the shop on the corner of the intersection with Ratchawong Road. The shop's name, 'Black Cat Union Co.,Ltd' (黑猫友聊有限公司), is conveyed in all three languages and records a bit of local lore, namely that the area had been known for the large number black cats inhabiting it before the construction of this building.

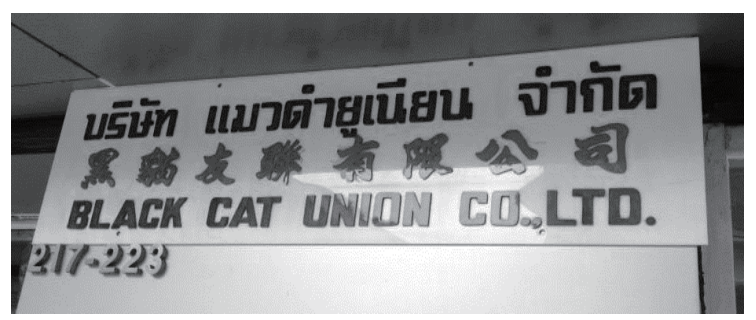

Picture 3: A sign of a shop selling various kinds of goods

Another strategy for the naming of shops is to include words for good luck or prosperity. Since Chinese people believe in good fortune, they name the shop by using words with positive denotations. As can be seen from Picture 4 the main sign over the front door and window of a dispensary, the Chinese name is 蔡東發. ‘ 蔡” is the owner's last name. ‘東' means 'East' which refers to China and '發' means 'prosperity and fortune'. The Thai script is the translation of the Chinese words that express a wish of prosperity for the shop. 


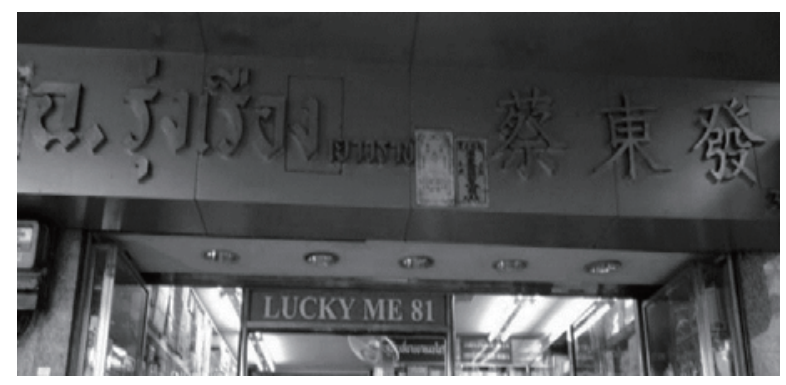

Picture 4: A dispensary in Chinatown

Some shop names are derived from the name evocative of an auspicious or otherwise significant place. Picture 5 is an example of a shop named after the Thai province of Lopburi, named so according to the shop owner of Lopburi Panit, because at the time, the province was a very prosperous city. The word 'Panit', which means 'commerce' in Thai, is used in many Thai stores to indicate that this shop sells merchandise. The English script is a transliteration of the Thai script, whereas the Chinese script consists of a transliteration of the word 'Lopburi' and the Chinese word for 'store' (商店).

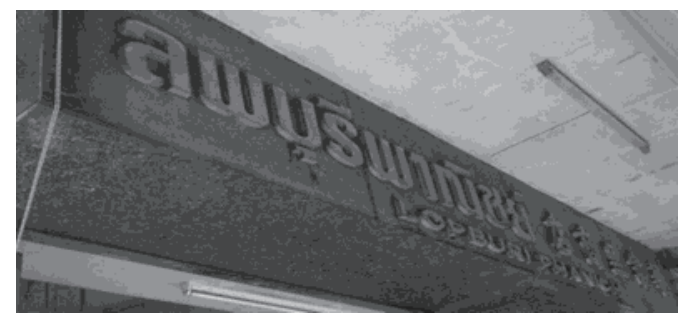

Picture 5: The Lopburi leather goods store

Finally, some shops employ multiple strategies across languages for the purpose of ease of remembering. In Picture 6, the Chinese name of one of the gold shops in Chinatown is 'Ma li xing da jin hang' (马 利兴大金行) which consists of family name, a good wish, and followed by 'gold shop.' But its proper name in Chinese has no relation to the Thai script. The Thai script is 'Hang-Khai-Thong-Thong-Bai Yaowarat'. 'Hang-Khai-Thong' simply means gold shop. Interestingly, 'ThongBai' means 'gold and leaf' which has no relation to the Chinese but it is named because this word can be easily remembered by Thai people.

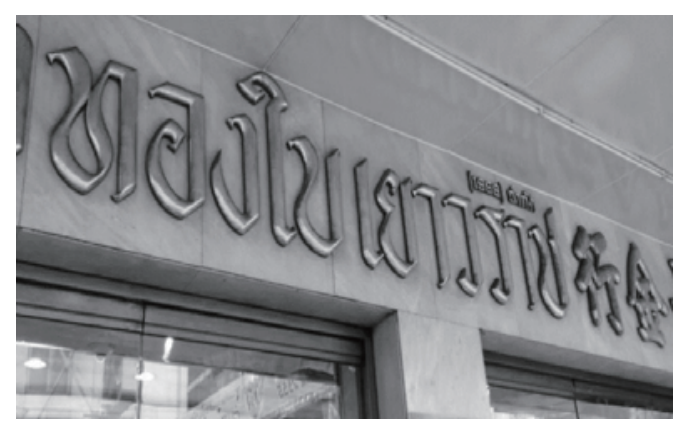

Picture 6: Thong-Bai Gold Shop

From the above mentioned six categories of the shop names, namely the first or last name of the shop owner, the products or services of the shop, the origin of the shop, the words for good luck or prosperity, the name evocative of an auspicious or otherwise significant place as well as the purpose of easy remembering, it can be concluded that the shop owners in Chinatown are still inclined to preserve the Chinese culture while they are adapting to Thai culture.

\section{Multilingual Information Arrangement}

In multilingual signs, the arrangement of information also reflects the relative status of the languages involved. Reh (2004) provides taxonomy of types of multilingual information arrangement. It includes: (1) duplicating, in which all of the information is presented in both languages; (2) fragmentary, in which the information in Language $A$ is totally included in the message of Language B, though Language A also contains additional information not found in Language B; (3) overlapping, where two 
or more languages share some information in common while each includes information not found in the other; (4) complementary, in which two or more languages covey completely different content. The overwhelming majority of the shop names in Chinatown Bangkok belong to the first three types, which contain complete or partial mutual translations. The example given in Picture 7 demonstrates the duplicating nature of Chinese-Thai bilingual signs. Both the Thai and the Chinese translate as 'Lao Tang Well-Known Spiced Goose.'

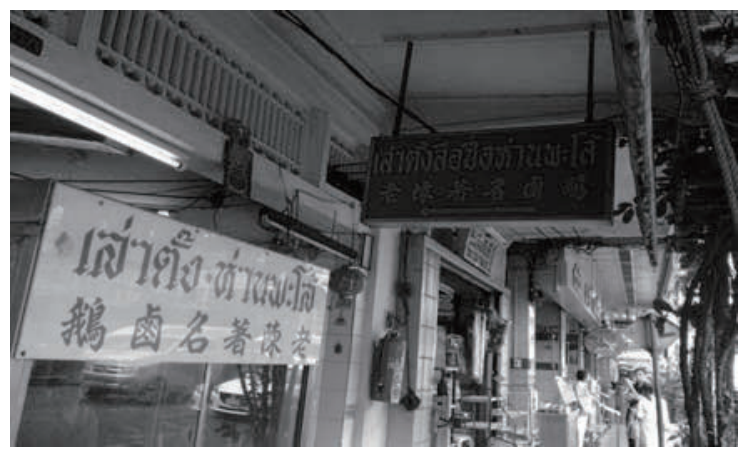

Picture 7: A restaurant selling spiced goose

A good example of a fragmentary sign is found in the trilingual sign in Picture 8.

Chinese: 蔡永發中西药行 (Cài yŏngfā zhōng xī yào háng)

Cai-Yongfa-Chinese-WesternMedicine-Pharmacy

'Cai Yong Huad Traditional Chinese Medicine and Western Medicine Pharmacy'

Thai: ฉ.มั่นคง (C. Mankong)

English: YONG HUAD
The Chinese portion of the sign contains the family name of the shop owner and the auspicious quality 'stability and fortune', i.e. 'Cai Yong Huad' (蔡永發) and its goods or service 'Traditional Chinese Medicine and Western Medicine Pharmacy' (中西药行), while the Thai contains only the proper name of the shop 'Yongfa', which means 'stability and fortune', translated into Thai, as 'มั่นคง' (Mankhong), with the abbreviation 'ฉ.' for the family name 'Cai'. The English transliteration contains only the auspicious word 'Yong Huad' without family name or indication of merchandise sold. Hence, Thai and English only partly represent the content of the shop name.

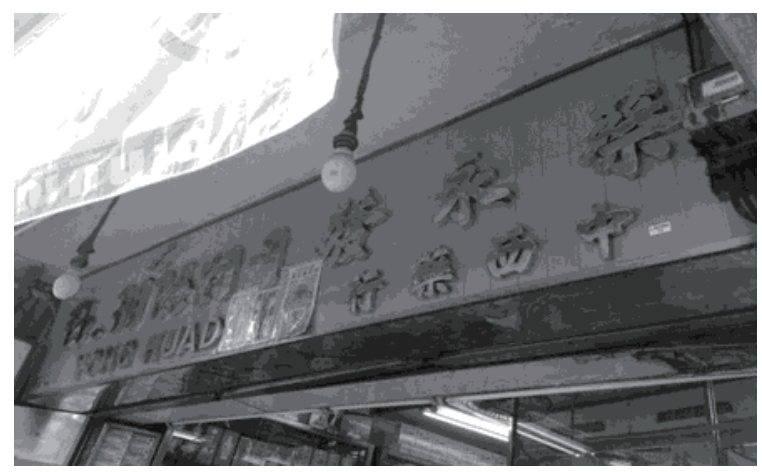

Picture 8: A shop selling traditional Chinese medicine

The example in Picture 9 is an example of the overlapping arrangement of information involving Chinese and Thai:

Chinese: 海外天鱼翅酒楼

(Hăiwàitiān yú chì jiù lóu)

Oversea-paradise-shark fin-restaurant

'HaiWai Tian' Shark fin Restaurant

Thai: เล่าลี่ หูฉลาม เยาวราช $(\mathrm{Lao} \mathrm{Li} \mathrm{Hu}$

Chalarm JAWARAT) 


\section{(English: Lao Li Shark Fin Chinatown)}

The Chinese version contains the proper name 'Overseas' and the type of establishment 'Restaurant' selling 'sharkfin', while the Thai name translates the 'shark-fin', and adds the family name 'Lao Li' and the location 'Yaowarat' or 'Jawarat'.

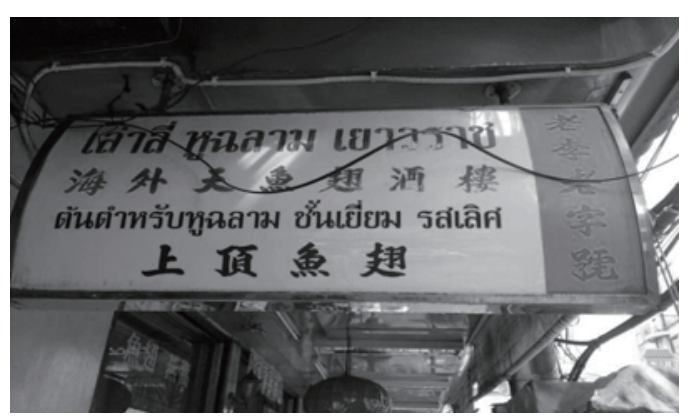

Picture 9: The extended sign of the shark fin restaurant

The complementary pattern of bilingual information arrangement can be seen in the use of Chinese and Thai in the major sign of the same shop, as shown in Picture 2.

$$
\begin{aligned}
& \text { Chinese: 海外天 (Hăiwài tiān) } \\
& \text { Oversea-paradise 'Haiwai Tian' } \\
& \text { Thai: เล่าลี่ หูฉลาม (Lao Li Hu-chalarm) } \\
& \text { (English: Lao Li Shark fin) }
\end{aligned}
$$

The Chinese in this sign only mentions the proper name of the shop, while the Thai indicates the family name of the owner: 'Lao Li' and the goods, 'shark fin'.

In our Chinatown corpus, most of the shop names are bilingual or multilingual, but the translation or transliteration from Chinese to the Thai or English versions represents only partially the content of the original Chinese name. The majority of these are transliterations of the Chinese. That is to say, the audiences cannot infer the meaning of the shop's Chinese name from Thai or English. In this case, Chinese names of the shop have only a symbolic function for Thai and English-speaking customers.

With regard to the lexicon found in the signs, most signs containing Thai and/or English are transliterations of the proper names based on the Teochew dialect spoken by the shop owners, though a few are translations containing information about goods and services offered, the auspicious characteristic that is a part of the original name, the shop's location, and so on. In contrast, most shop names in Chinese contain the Chinese character '記' (Ji) or '行' (Háng), which originated during the Ming or Qing dynasty as a distinctive mark for shops. These Chinese characters have no equivalent in the Thai or English translation.

A closer look at the Chinese names reveals that they follow Chinese grammar of 'modifier + head', while the Thai versions follow Thai grammar of 'head + modifier', for example the description of shark-fin in Picture 9,

\section{Chinese: 上顶鱼翅 (Shàngdı̆ng yú chi)}

High quality-shark fin

'High Quality Shark-fin'

Thai: ต้นตำหรับหูฉลาม ชั้นเยี่ยม รสเลิศ

(Ton-tam-rub-hu-chalarm chan-yiam lot-lert) 
(English: Original Shark-fin Quality High Tasty)

Unlike the Thai-English hybrid variety (Huebner 2006) resulting from contact, interaction and the reciprocal influence of one language on the other, in this language contact situation, Chinese and Thai each still preserves its own syntax without much influence from the other. This might suggest the use of language, and particularly Chinese, for symbolic functions rather than as a living language used in contact with Thai. In other words, for the target customers who are tourists and non-literate in Chinese, the Chinese name represents no more than the commodification of Chinese culture, lending a sense of authenticity to the shopping experience. But for ChineseThais, both shopkeepers and regular customers alike, the Chinese characters and their transliterations exert a more symbolic function, representing a tangible tie to their cultural heritage.

Leeman and Modan (2009) analyze the meaning of the display of minority languages in commodified spaces, and suggest that signs have various levels of meaning that may be influenced by the context of the signs' immediate setting (micro-level): adding value to the products or services offered. It seems to be true as well for the shops of Chinatown in Bangkok. The owner of the Chiang-Pu Fruit Shop, for example, mentioned that China nowadays is an emerging economic power, so the Chinese language also adds value and prestige to the products. Additionally, the statistics mentioned in the quantitative analysis above, together with our interview data, suggest that owners include English in the shop names to add a sense of multilingualism and internationalism. A comparison of Picture
5 and Picture 10, a picture taken over twenty years ago by the shop owner), shows that the English name emerged later than Thai and Chinese names to give the shop an international flair from the owner's view.

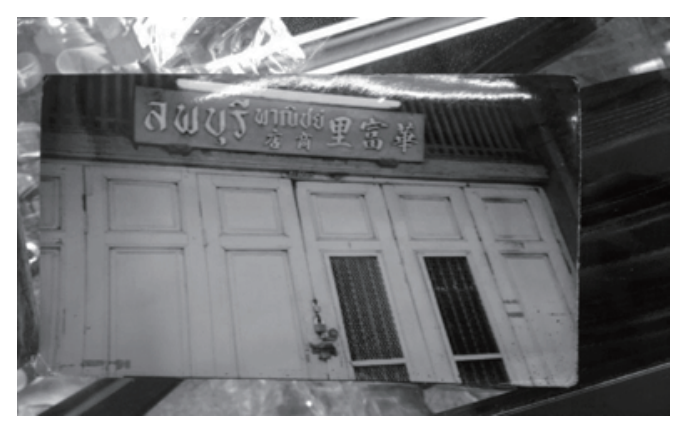

Picture 10: The Lopburi leather goods store was taken over 20 years earlier (cf. Picture 5)

\section{Spatial Organization of Shop Signs}

Kress and Van Leeuwen (1998:188) postulate "three signifying systems, all serving to structure the text, to bring the various elements of the pages (e.g. photographs, headlines, and blocks of text) together into a coherent and meaningful whole". These systems include salience, framing and information value, which provide a good viewpoint for the analysis of the shop names of Chinatown in Bangkok. As pointed out above, most of the shop names are on major signs attached to the surface of the store front; some shop signs employ traditional Chinese characters inscribed horizontally and a few of the shop names are in modern sans-serif font. For the bilingual and multilingual signs of the shop names, it seems that both Thai and Chinese take up equal space and almost the same size of font. Normally, Chinese names are short and simple within 10 traditional Chinese characters, while Thai is always longer 
than Chinese, a function of the Thai alphabetical orthography in contrast to the Chinese logosyllabic system. The shop names in Thai are usually in modern Thai font without serifs. The Chinese preserves the traditional characters which had been used in China for about two thousand years, until a simplified set of characters was introduced in the People's Republic of China in the last century. The traditional characters are still used predominantly in overseas Chinese communities (with the exceptions of Malaysia and Singapore), Taiwan, Hong Kong and Macau. English appears in upper case. A large proportion of the Chinese shop names are in horizontal layout except some shop names placed outside the building in the vertical layout. Moreover, Thai and Chinese in the majority of the shop names are arranged side-by-side and adopt the popular traditional Chinese colors of gold and red.

Huebner (2009:76) pointed out that "of the three signifying systems that structure the text, information value is most clearly linguistic in that it concerns the pragmatic distinction between given and new, as well as the distinctions between ideal and real, and central and ancillary." Applying this hypothesis to the shop names in Bangkok's Chinatown poses some problems, especially for some of the multilingual signs.

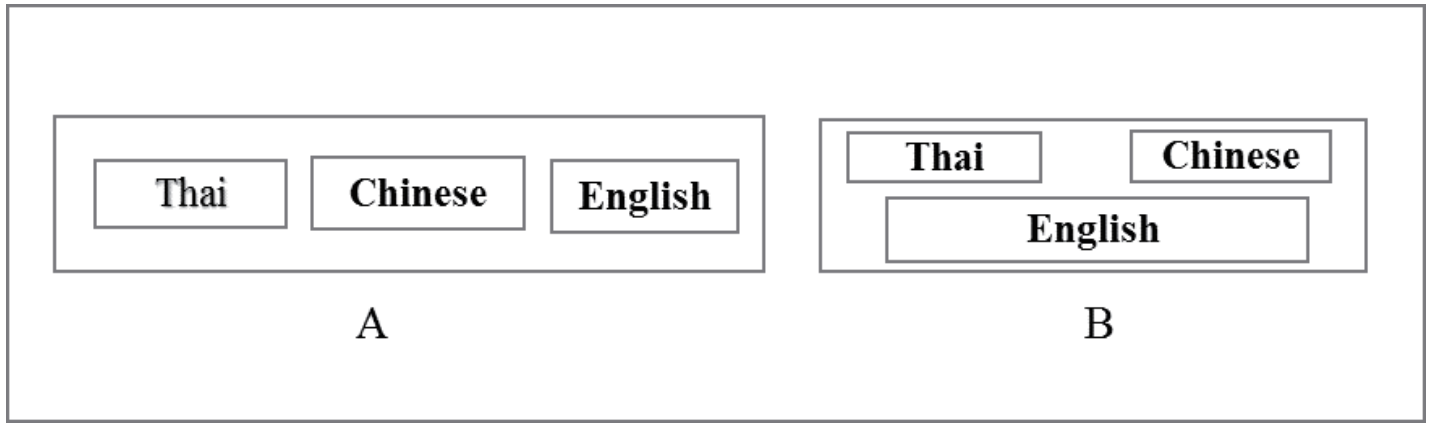

Figure 1: Layout of the shop names in multilingual signs.

As shown in Figure 1 above, the layouts of most shop names are as type A or type B, and type $\mathrm{A}$ appears less frequently than type B. In type A signs, the language in the middle may be considered central and the language to the left and right of it may be considered peripheral. Among the shop names in Type A, eight are with Chinese in the middle, and only three are with Thai in the middle. In this sense, in Type A Chinese is deemed as central, and Thai or English as peripheral. However, in Type B signs, Thai is placed on the top left side, and Chinese is on the top right side. If there is English, it is always below the Thai and Chinese names. Among the multilingual shop names, besides eleven shop names with Chinese on the top left side, two shop names have English names appearing on the top left side, while other sixty-four shop names show Thai on the top left side. According to Kress and Van Leeuwen, for a left-to-right layout, the element on the left is presented as Given, and the element on the right as New. Therefore, in both Type A and B, Thai (on the top left side) is most often the information supposedly known to all. 
Chinese is presumably the new information unknown to the addressee. As the aforementioned interview data suggest, most of the target audiences as well as many of the shop-keepers themselves are Thai speakers, so it is natural to generalize that Thai is the given information and Chinese is the new information.

However, the situation is a bit more complicated. Among the horizontal shop signs containing Chinese characters, there are two possible lay-outs, left-to- right and right-to-left. Forty-three of them read leftto-right, and sixty read right-to-left. This calls into question the generalizations made in Kress and Van Leeuwen's Grammar of Space and Spatial Organization, which is based on left-toright reading European languages. For the sixty right- to-left signs, should the Chinese information be perceived as given? What are the implications for a bilingual sign that reads in Thai left-toright and in Chinese right-to-left? These are the potential problems faced in the interpretation of the shop names of Chinatown of Bangkok. Regardless of the theoretical implications for a grammar of space, the right-to-left reading is another feature of an older, more traditional time that is preserved in the linguistic landscape of Chinatown.

In the spatial arrangement of languages on shop signs in Chinatown, both Chinese and Thai are given prominence. Through the use of popular colors of Chinese style, the Chinese mark of shops (記 'Ji' and行 'Háng'), use of traditional Chinese characters of equal size as Thai, and the reading of Chinese characters from right to left shop, owners tend to preserve the traditional Chinese culture reminiscent of the China their ancestors left behind, even though the current generation sees themselves as having a mixture of Thai and Chinese culture.

\section{Conclusion}

In this paper we investigated the linguistic landscape of Bangkok's Chinatown from different perspectives, both quantitatively and qualitatively, to explore how shop owners preserve the Chinese language and culture under the circumstance of language contact with Thai and more recently English. We found that many of the shop signs are written in Chinese orthography with transliterations from the Teochew pronunciations into Thai and English. The shop names can be categorized into six types according to the content, reflecting traditional Chinese values and practices and evoking feelings of nostalgia among the older generation of Chinese descendants. They preserve the Chinese style to some extent with respect to popular colors, the symmetrical layout, the mark of the shops '記' (Ji) and '行' (Háng) and the traditional Chinese characters. At the same time, Chinese fulfills a symbolic function creating in Chinatown a commodified space which adds value and appeal for tourists.

An examination of the multilingual arrangement of information reveals that Chinese and Thai follow their own specific grammars without evidence of hybrid language. Most of the Thai appearing in the signs involves transliteration of the proper names with some supplementary information translated in the extended sign of the shop names, suggesting that the large majority of readers who are likely to be customers are Thai, including Chinese-Thais who cannot read Chinese. From the perspective of the grammar of space, it was seen that the Thai language is given more 
prominence than Chinese, again in deference to Thai customers. At the same time, it was shown that the Kress and Van Leeuwen framework for the analysis of spatial organization may not be applicable to Asian languages that don't necessarily read from left to right. .

Our qualitative data also revealed an emerging pride among the younger generation of Chinese-Thais in the language and culture of China, though not necessarily in the dialect of their ancestors. How this budding awareness plays itself out in the next generation within the context of China's increasing presence and influence in Southeast Asia is a topic for future studies.

The arrangement of the information in multilingual signs as well as the grammar of each language suggest that Chinese plays a symbolic yet significant function while Thai carries more information for the customers and English is a trend for shop names under the circumstance of globalization.

\section{References}

Landry, R. and Bourhis, R.Y. 1997. Linguistic landscape and ethnolinguistic vitality: An empirical study. Journal of Language and Social Psychology 16. 1: 23-49.

Backhaus, P. 2006. Multilingualism in Tokyo: A look into the linguistic landscape, International Journal of Multilingualism 3. 1: 52-66.

Bruyèl-Olmedo, A. and Juan-Garau, M. 2015. Minority languages in the linguistic landscape of tourism: The case of Catalan in Mallorca. Journal of Multilingual and Multicultural
Development 36. 6: 598-619.

Cenoz, J. \& Gorter, D. 2006. Linguistic landscape and minority languages, International Journal of Multilingualism 3. 1: 67-80.

Hauser, S. (n.d.). History of Bangkok's Chinatown. 19 December 2015 $<\mathrm{http}$ ://safechild.org/categoryparents/ safety-on-the-internet/>.

Huebner, T. 2006. Bangkok's linguistic landscapes: Environmental print, codemixing, and language change, International Journal of Multilingualism 3. 1:31-51.

Huebner, T. 2009. A framework for the linguistic analysis of linguistic landscapes. In E. Shohamy and D. Gorter (eds) Linguistic Landscape: Expanding the Scenery. New York: Routledge.

Ivkovic, D. \& Lotherington, H. 2009. Multilingualism in cyberspace: Conceptualising the virtual linguistic landscape. International Journal of Multilingualism 6. 1: 17-36.

Kasanga, L.A. 2012. Mapping the linguistic landscape of a commercial neighbourhood in Central Phnom Penh. Journal of Multilingual and Multicultural Development 33. 6: 553567.

Kress, G. and Van Leeuwen, T. 1998. Front pages: (The critical) analysis of newspaper layout.In: A. Bell and P. Garret (eds) Approaches to Media Discourse, Oxford: Blackwell. 
Lawrence, B.C. 2012. The Korean English linguistic landscape. World Englishes 31. 1: 70-92.

Leeman, J. \& Modan, G. 2009. Commodified language in Chinatown: A contextualized approach to linguistic landscape. The Journal of Sociolinguistics 13. 3: 333-363.

Lou, J. J. 2010. Chinese on the side: The marginalization of Chinese in the linguistic and social landscapes of Chinatown in Washington, DC. In E. Shohamy, E. Ben- Rafael and M. Barni (eds), Linguistic Landscape in the City. Bristol: Multilingual Matters.

Moriarity, M. 2015. Indexing authenticity: The linguistic landscape of an Irish tourist town. International Journal of the Society of Language 232, 195-214.

Reh, M. 2004. Multilingual writing: A reader-oriented typology ---with examples from Lira Municipality (Uganda), International Journal of the Sociology of Language 170:1-41.

Thai Chinese (n.d.). December 20, 2015 $<$ https://en.wikipedia.org/wiki/ Thai_Chinese>. ดอกบ๊วย. (2008, May 7). การศึกษาภาษาจีนในประเทศไทยตอนที่ ๓ [The study of Chinese in Thailand. Part3]. December 15, 2015 $<$ http://www.oknation.net/blog/ sirinui/2012/06/03/entry-1>. 